\title{
Do Micro-Credits Work As An Effective Anti-Poverty Program For Poverty Eradication? Evidence From Ethiopia
}

https://doi.org/10.21272/sec.3(2).31-53.2019

\author{
Weldeslassie Hailai Abera \\ PhD Candidate, University of Kwa-Zulu Natal, Durban, South Africa
}

\section{Cliare Vermaak}

$\mathrm{PhD}$, Senior Economic lecturer and researcher, Department of Economics, School of Accounting, Economics and Finance, College of Law and Management Studies, University of KwaZulu-Natal, South Africa

\begin{abstract}
This review outlines the debates and questions within the quasi-experimental analysis on whether micro-credits have created the impact. The primary purpose of the research deals with the pillar questions do microcredits play an efficient anti-poverty strategy to eradicate poverty? Do micro-credits generate the proposed products and results by raising the living standards of micro-finance clients and do beneficiaries become less poor after they get the micro-finance service as compared with those under comparable conditions but who do not have access.

Methodization empirical causes and techniques for explaining the intrinsic challenges in untangling and identifying the impact of an intervention program is a hard task since this method analyses the plight of recipients before and after a program that may capture not merely the impact because of the unique intervention but still other impacts that should have resulted even in the program's absence. Comparing the condition of beneficiaries after the intervention with the counterfactual situations examining what would have happened to them in the project's absence and what kind of service or goods beneficiaries would have access to instead of the offered by the intervention requires scrutiny, time-consuming and is the greatest challenge that makes thoughtful planning, capabilities, and execution. The rational and relevance behind the resolutions for implementing the scientific question of impact analysis is a crucial tool to enable policymakers to decide whether redesigning anti-poverty intervention the program, scale it up, interrupt it or designs similar intervention schemes for other societies.

Investigation of the matter 'Do micro-credits work as a valuable anti-poverty program for Poverty Eradication? We carry evidence from Ethiopia 'in the paper out in the following logical sequence: we first estimated propensity scores for participation on several pre-treatment variables. We then matched clients and non-clients based on these. Next, we estimated the average treatment effect, regarding participation as a treatment, and participants as the treated group.
\end{abstract}

Methodological tools of the research methods were propensity impact analysis procedure using the 2009 dataset from four locations in northern Ethiopia. The paper presents the results of an empirical analysis of the impacts of micro-credits on poverty reduction, which showed that micro-credits have a short time significant impact on household small (productive assets), on human capital investment (expenditure on buying school material and health). Equally noteworthy, we found MFIs to have a vital effect on family spending on food, non-food items, and poverty severity.

JEL Classifications: G2, G20, G21, G23.

Keywords: microcredits, poverty, impact analysis, counterfactuals, propensity score matching.

Cite as: Weldeslassie, H.A., Vermaak, C. (2019). Do Micro-Credits Work As An Effective Anti-Poverty Program For Poverty Eradication? Evidence From Ethiopia. SocioEconomic Challenges, 3(2), 31-53. https://doi.org/10.21272/sec.3(2).31-53.2019.

(C) The Authors, 2019. This article is published with open access at Sumy State University. 


\section{Introduction}

Many have praised Microfinance to be one of the most powerful weapons in combating international poverty in the developing world. It has been principally impressive and valuable in contributing to products such as savings deposits, insurance, and credit to the unserved and under-served in the developing and transitional economies, those that do not possess the collateral or credit histories to satisfy the demands of traditional financial services. Micro-finance aims to "create economic and social development from below" (Julien K 2009: PP-3). As a point in the case, in 2006, while awarding Nobel Peace Prize to Muhammad Yunus, "the godfather of micro-credit" Nobel Committee called it "an important liberating force."

Some researchers contended that it is wishful thinking to believe that tiny loans to poor people in the developing world can end poverty, yet micro-finance does, in fact, improve the lives of millions in small but meaningful ways (Boudreaux et al., 2009).

This study summarizes the arguments and counterarguments within the scientific discussion on whether micro-credits have caused the impact since we design them in lifting the poor out of poverty. The main purpose of the research tackles the key questions do micro-credits serve an effective anti-poverty intervention scheme to obliterate poverty? Do micro-credits generate the expected outputs and outcomes by enhancing the living standards of micro-finance clients and do beneficiaries become less poor after they get the micro-finance service as compared with those under similar conditions but who do not have access.

We should carry out the development and extension of micro-credit unleashed vibrant debates and many disagreements on its capability to exterminate poverty for those who take it up (Woller, Dunford, and Woodworth, 1999; Rhyne, 1998; Bhatt \& Tang, 2001; Woller \& Woodworth, 2001; Gonzalez-Vega, 1998; Morduch, 1998; Khandker, $2001 \&$ 2005; Pitt and Khandker, 2001; and Berhane \& Gardebroek 2009).

Micro-finance institutions in developing countries should increase incomes, reduce poverty, and create a fair distribution of capital by creating job opportunities; sustain agricultural development and serve as vanguards of for industrialization; create competent and sustainable economic growth and diversity SMMEs' development by creating capital and spurring innovation.

However, we should regularly scrutinize government anti-poverty interventions in terms of their contributions to job creation, poverty alleviation, total final output production, and women's empowerment. The possible sectoral, industrial, market, institutional and industrial linkage, growth and sustainability. We question whether micro-finance aroused the poor to develop enterprises that benefit them to contribute considerably to eradicating poverty/improving the living standard of clients after taking the loan. We contend that in developing countries such as Ethiopia, micro finances seemed to have a negligible impact to assist the bottom poor to climb out of the extreme poverty and bring about a social transformation in the informal credit sector by creating massive-scale credit access to the disadvantaged and inspiring enterprise development and entrepreneurship, although it might support the poorest population from a disastrous shock to keep the soul in its body.

Not merely the interaction between micro-finance and poverty but again the methods of determining the impact of micro-finance is complex, and continues to be open-ended challenges where scholars have diverse views on the functions of micro-finance strategies to obliterate poverty.

On top of the numerous discords of thoughts, we believe there is an insufficient analysis on impact research that examines non-food per capita consumptions and productive family resources that are assumed to be the strongest gauges to assess well-being/living standards of micro-finance clients after they take the micro-credit services. Aiming to provide empirical evidence for the relationship between micro-finance and poverty, we use 2008 and 2010 family survey data from Northern Ethiopia.

The key research questions we intend to tackle in this research are:

1. Do micro-credits work as an Effective anti-poverty program for Poverty Eradication? Evidence from Ethiopia?

2. Do the living standards of micro-finance clients improve and become less poor after they get the microfinance service/they borrow the money and have access to micro-credits or those who take it up between DECSI clients and non-clients? 
Is there a significant difference in well-being indicators such as family per capita expenditure on (food and non-food goods and services)? Family per capita productive and fixed asset ownership between DECSI beneficiaries and non-clients?

\section{Problem Statement and Succulent Examination of the Relevant Literature}

The schism of theories and discrepancy of views among intellectuals, benefactors, development agents, analysts, policymakers and specialists on micro-finance services ability to lift the poorest of the community out of indigence, promote entrepreneurship, inclusive growth and whether they are effective tools in the lens of anti-poverty social programs and to what degree do they assist the bottom poor to wipe out poverty and improve the living standards have become the wrestling ground of thoughts over the last two decades. The development and extension of micro-finance unleashed vibrant debates and multiple rifts on its effective capability to reduce poverty and how and for whom we should deliver.

Researchers and practitioners give various names based on the technology they should use in financial services, or 'minimalist,' approach vs an 'integrated' service concept; 'institutionalists' vs 'welfarist' approach; financial deepening (financial viability and fitness) vs deepening outreach (the level of poverty reached, i.e., if they are less poor after the taking part in micro-finance); client-centered micro-finance vs institution-centered micro-finance services and cost-benefit analysis approach. A wealth of literature (Woller, Dunford and Woodworth, 1999; Rhyne, 1998, 1999; Bhatt \& Tang, 2001; Woller \& Woodworth, 2001; Morduch 2000; Olivers-Polanco, F., 2005) have documented these discrepancies of thoughts.

On one hand, exponents of the institutionalist approach e.g. the World Bank and Consultative Group to Assist the Poor (CGAP) and USAID (Woller, Dunford, and Woodworth, 1999; Rhyne, 1998; Bhatt \& Tang, 2001; Woller \& Woodworth, 2001; Gonzalez-Vega, 1998; Morduch, 1998; Morduch, 1999a; Morduch, 1999b; Morduch 2000; Morduch, 2007; Morduch, 2007b; and Morduch and Roodman 2009) relate to these two positions as the micro-finance schism with its intensity on who is being served, attaining financial sustainability; breadth of outreach, financial deepening, and progress in institutional scale and success towards achieving financial self-sufficiency. Besides, they argue that building small loans fuel economic self-sufficiency and have positive impacts on living standard and poverty reduction.

Critiques of micro-finance cast significant uncertainty, especially on the type and extent of micro-finance's successes, contending that micro-credits does not address the economic problems of the poorest of the poor, empower women nor stimulate the advancement of SMEs. They further claim that if micro-finance addresses anything at all, it either benefits the middle-poor or helps the poor to just survive (Arun et al. 2006; Boudreaux and Cowen, 2009; Kondo et al., 2008; Armendáriz de Aghion and Morduch, 2005).

Corresponding, casting serious doubt on the commercializing tendencies of this sector, the welfarist camp (e.g. Khandker, 2001; Pitt and Khandker, 2001; Khandker, 2005; Woldehanna, 2005; and Berhane \& Gardebroek, 2009), in contrast, prioritize deepening outreach (the levels of poverty reached) contend that the world's most weak people are in no position to take on the risks of entrepreneurship. They point to evidence showing that stable jobs in large industries, not volatile small businesses, and lift people out of indigence.

This camp thinks we should appraise MFI performance in terms of the impact on the welfare of the poor. Succinctly, the welfarist approach deals not only with the challenge of how poor the clients are but whether they are less poor after they gain the money (Cheston \& Reed, 1999).

A research directed by Christen (2001), reported that people have known micro-finance clients to economize on food, sell their appliance, borrow from loan sharks, and take second jobs to pay off their loans that spouses, sons, and fathers-in-law often take control of women's loans and that, overall, micro-finance does not find its way to the world's poorest people. In a nutshell, studies in this area are inconclusive.

Considering these diversities in views and the arguments in the configuration and implementation of microfinance institutions, this study analyses whether micro-credit schemes help to reduce poverty measured in terms of a family's food and non-food expenditure, explores their impact on household productivity and clients' fixed asset holdings. It examines the micro-credit impact on several key household poverty indicators.

The sector is dynamic, huge resources are assigned and conveyed; it influences the daily lives of millions of disadvantaged and the poorest of the poor. Therefore, appropriate refinements are expected in the metaphysical, scholarly, empirical and policy research approaches and procedures. Further empirical evidence on the 
poverty-reducing effects of access to micro-finance and its impact on clients using data gathered from four rural tabias (local administrative units) Tsekanet, Rubafeleg, Arato, and Siye, which are in four woredas in different zones of the Tigray Region.

To sum up, our view is that, however, micro-finance may help households to tread water in when they face unforeseen shocks and become sensitive; i.e. through migration or sale of draft animals (bought from credit) when facing idiosyncratic shocks, and families may avoid a loss of human capital. Therefore, their impact on household fixed assets and various poverty indicators must be constantly evaluated.

\section{The significance of the study}

This investigation advances to the society of learning on quasi-empirical impact evaluation, to the current deliberations on whether micro-financing is useful poverty intervention program to erase poverty since we allocate too as enormous capital, they have been transmitted others wise to other profitable investment opportunities. This consideration will contribute as a basis for further research on whether micro-we can consider finance institutions as a vanguard of entrepreneurial incubations, and pave the path to the advancement of small, micro and medium enterprises (SMMEs).

This research is likewise noteworthy to those who are committed in the arrangement and implementation of micro-finance, governments, NGOs, philanthropists and the beneficiaries to rethink the credit delivery mechanism and to integrate them with the low-cost innovative technologies of inclusive credit and saving service provisions.

\section{Empirical Strategy, Research Design, and Data}

The subsequent category briefly displays the empirical strategy we applied for this investigation, research schemes, explanation of Dedebit Credit and Saving S.C (DECSI) micro-finance institution (MFI) and data.

\section{Brief Statement of the DECSI and MFIs in Northern Ethiopia}

We assemble the origin of the data used for this research from rural families in the regional state of Tigray, northern Ethiopia, where Dedebit Credit and Saving Institution S.C. (DECSI) was formed and operate as a Microfinance Institution (MFI). To shed more light on the environment of DECSI, the National Bank of Ethiopia established and certified it, conforming to Decree No.40/1996 in 1997. It expanded from a program started by the Relief Society of Tigray (REST), a local "Non-Governmental Organization (NGO)" based in Tigray, northern Ethiopia, it was founded in 1978 as an institution providing relief efforts to citizens. REST emerged as the humanitarian branch of the Tigray People's Liberation Front (TPLF) ${ }^{1}$ and has lived firmly bound to the TPLF.

In 1993, a study coordinated by REST launched a socio-economic study on rural underdevelopment, starvation, deprivations and poverty in Tigray that revealed huge unsupplied/gap or inadequacy of access to financial functions and credit by the agrarian poor was determined as one of the principal impediments to the reconstruction of lives and subsistence, peace-building and overall socioeconomic improvement in the Tigray people that were turning up from a protracted and devastating civil war. As a result, REST established the Rural Credit Scheme in Tigray (RCST) (it began the first action in 1994) under auspices of REST (Borchgrevink, Valle, and Woldehanna 2005). They created an anti-poverty intervention program aiming at enhancing rural production, spurring the local economy, trimming the influence of traditional moneylenders/usurers, creating jobs and entrepreneurial opportunity, boosting earning for the underprivileged and stimulating urban-rural linkage and so forth.

Besides, the mission of DECSI may be worked out improving the well-being of families/individuals who were/are dispossessed of getting financial supplies from the formal banking system, by burgeoning their income and wealth by rendering ultimate quality and sustainable financial services to the poor. Considering ownership structure, DECSI is a share company established off and the National Bank of Ethiopian. The shareholders the Government of Tigray Regional State (25 percent) and 75 percent are shared among the REST (which takes the lion's share), Women's Association of Tigray, Farmers' Association of Tigray and

\footnotetext{
${ }^{1}$ Tigray People Liberation Front (TPLF) is one of the key members of the Ethiopian People Revolutionary Democratic Front (EPRD), which was formed in 1989, is currently the ruling 'political coalition' in Ethiopia. be scrutinized.
} 
Youth Association of Tigray. Donors of DECSI include Norwegian People's Aid, International Fund for Population Development (IFPD), Glimmer of Hope, RUFIP Scheme and the International Agricultural Development Fund. DECSI has loans from the Development Bank of Ethiopia and the Commercial Bank of Ethiopia and receives matching funds from the Ethiopian government, including the Bureau of Trade and Industry and the Food Security Coordination Office.

Moving on, even though clients differ corresponding to the output services, DECSI determines the target groups of DECSI as Community members striving to come out of poverty; the poorest of the poor capable of generating income/ productive poor/; and owners of micro, small and medium enterprises (SMMEs).

Considering outreach, having over 2000 staffs DECSI has been delivering its functions via functionally decentralized over 120 sub-divisions, over 9 main branch departments and over 15 micro-finance collateralbased subsidiaries. Correspondingly, DECSI delivers four types of financial services credit, saving money transfer, pension amounts and gold management.

Besides, modalities of loan arrangements are in a group, independently and through collateral. Considering loan types delivered to applicants, regular loan (presented to regular clients with minimum 3 group guarantee); it carried agricultural input loan (100 percent for purchase of modern agricultural inputs such as fertilizer, selected seed, farming out in partnership with Rural Development Bureau); civil servants loan (to cover education fees, housing construction/purchase, etc.); rural package/household centered loan, urban package loan, business loan, housing loan, university and college graduates loan, equipment leasing loan, reconstruction and war vets loan and so forth.

To succulently illuminate impacts of DECSI programs, DECSI claims that up to now Ethiopian Birr (ETB) over 5 billion(or 125 million USD) loan is contributed to its clients; out of which over $50 \%$ is given chiefly for advancing agricultural production. DECSI has played a critical role in stimulating saving and micro-finance over 190, 000 household saving account clients.

\section{Research Method, and Data}

We have gathered the data used for this research from tabias/kebeles ${ }^{2}$ in northern Ethiopia using two-stage sampling methods. The primary sampling were tabias. The practice of sampling tabias was determined based on a piece of secondary information picked up from all woredas. Socioeconomic driving factors like distances to markets, geographical position, both rain-fed, and irrigated agricultural systems, the representativeness of zones and the population sizes of tabias taken in accounting.

Next, four tabias namely, Arato (Enderta-Woreda) in the Southeastern zone, Tsenkanet (Saese-tsaeda-EmbaWoreda) and Rubafeleg (Atsbi-Womberta-Woreda), both in the Eastern zone, and Siye (Tanqua-AbergeleWoreda) in the Central zone were randomly selected.

The tablas selected based on altitude, are representatives of the three agro-ecological zones of the Tigray regional state.

Considering Agro-ecological zones in the study area, areas with the altitude ranging from 1500 to 2300 meters above sea level are locally known as when dogma (i.e., roughly midland areas); areas above 2300 meters above sea level are locally said to be dogma (i.e., high land /temperate/ areas); and we refer areas with altitude as kola (i.e., lowland /tropical/zone). Two tabias are in woina dogua, one dogua and the fourth is kola.

From a sampling frame/number of a family list of each tabia, we used a proportional random sampling according to the size of families/households in each tabia. To this effect, the contribution of each tabia to the sample size was: 113 (Arato), 106 (Senkanet), 109 (Rubafeleg) and 103 (Siye). We asked the multi-purpose questionnaire to the household heads. Sometimes, where the women are more involved, both men and women took part in answering the questions. Finally, the number of a household being selected in the sample, a group of 12-13 households, 2 groups in each tabia were selected for the group deliberation.

\footnotetext{
${ }^{2}$ A tabia/kebele is the smallest administrative units/divisions in Ethiopia, similar to a ward, a neighborhood, or a localized and delimited group of people. Each tabia/Kebele is consisting of at least 500 families/households or roughly equivalent to 3,500 to 4,000 persons. It's also part of a woreda (district) in which a group of a group or a number of tabias/kebels come together under one umbrella to form smaller subdivisions called woreda or districts.
} 
We established these research fields in the Gibba Catchment area and are the best representatives of most of the lowlands and highland of Tigray. We selected these research stations by MU-IUC which is a ten-year partnership between Mekelle University, Ethiopia and the Flemish Inter-University Council, Belgium). For details, (see Fredu, 2008). A multi-purpose questionnaire has thus been applied a mechanism to collect information on family food and non-food expenses, household income (including income from off-farm activities), household products and durable resources, family participation in micro-finance and other sources of lending and so on. We covered although 431 households in the survey; it boiled down to 387 owing to the attrition rate, non-response error and close 33 household/members were new participants that impact of the interference cannot be investigated because of the short duration.

\section{Method and Econometric Analysis}

We applied the most accepted approach to measuring poverty, as recommended by Foster et al. (1984). Since our data is defined to diaries of family expenditures/consumption in the last 7 days before the interview date and the multipurpose questionnaire does not include detail data on other relative household poverty indicators, we adopted the FGT which measures poverty set in a condition in which the individual's basic needs are not covered there is a lack of basic goods and services (normally related to food, housing, and clothes). This approach of poverty measurement and analysis is strongly linked to destitution and can apply to all countries or societies. We classify a person who is considered poor under this criterion in the same way by many kinds of research in the developing world. Headcount index:

$P_{0}=1 /{ }_{N} \sum_{i=1}^{N} I\left(w_{i} \leq Z\right)=\frac{N_{p}}{N}$

where is the total community, and is an indicator function that takes a value of 1 if the bracketed expression is true, and 0 otherwise? Therefore, if an expenditure is less than the poverty line, then equals 1 and we examined the household poor. Is the total number of the poor.

1. Poverty gap index:

We define the poverty gap $\left(G_{n}\right)$ as the poverty line $(Z)$ less actual income $\left(w_{i}\right)$ for poor individuals; the gap is considered being zero for everyone else and can be specified $G_{n}=\left(Z-w_{i}\right) \cdot I\left(w_{i} \leq Z\right)$ : Then, the poverty gap index $\left(P_{1}\right)$ may be written as

$$
P_{1}=1 / N \sum_{i=1}^{N} G_{i} / Z
$$

2. Squared poverty gap index:

By squaring the poverty gap index, the measure implicitly puts more weight on observations that fall well below the poverty line, given by

$$
P_{2}=1 / N\left(\sum_{i=1}^{N} G_{i} / Z\right)^{2}
$$

We can summarize the three equations stated above in one equation given by Foster et al. (1984):

$$
P_{\alpha}=1 / N\left(\sum_{i=1}^{N} G_{i} / Z\right)^{\alpha},(\alpha \geq 0)
$$

Where $\alpha$ is a system of the sensitivity of the indicator to poverty and where the poverty line is $z$, the amount of the consumption per capita for the $j-t$ th person's family is $x_{j}$, and the poverty gap for an individual $j$ is $G_{j}=z-x_{j}\left(\right.$ with $G_{j}=0$ when $\left.x_{j}>z\right)$ when a framework $\alpha=0, P_{0}$ is the headcount index. When $\alpha=1$, the index is the poverty gap index $P_{1}$, and when $\alpha$ is set equal to $2, P_{2}$ is the poverty severity index.

The estimate will normally be based on a set of poverty lines (for our study, we estimated the poverty line, which is seen to be the minimal "standard of living" needed to be non-poor) computed by (Fredu, 2008) for 
the same sites. We have tackled all needed price adjustments, as there were alarming price rises in Ethiopia in 2008/09 due to internal and external reasons. Based on the cost of a basic needs approach, Fredu (2008) get 828 ETB and 1008 ETB for the food and total poverty lines. Thus, equation (1) - (4) above are vital for appraising the poverty profile of the study area.

\section{Conceptual Frameworks and Methods}

Methodization empirical causes and techniques for explaining the intrinsic challenges in untangling and identifying the impact of an intervention program is a hard task since this method analyzes the plight of recipients before and after a program that may capture not merely the impact because of the unique intervention but still other impacts that should have resulted even in the program's absence. Comparing the condition of beneficiaries after the intervention with the counterfactual situations examining what would have happened to them in the project's absence and what kind of service or goods beneficiaries would have access to instead of the offered by the intervention requires scrutiny, time-consuming and is the greatest challenge that makes thoughtful planning, capabilities, and execution. The rational and relevance behind the resolutions for implementing the scientific question of impact analysis is a crucial tool to enable policymakers to decide whether redesigning anti-poverty intervention the program, scale it up, interrupt it or designs similar intervention schemes for other societies.

Impact evaluation estimates we can attribute the differences/improvements in the well-being of individuals to a project, program, or policy. The principal problem of impact assessment is counterfactual; i.t. what would have been the beneficiaries' outcome in the intervention's absence? To express it differently, what would have been the condition of the living standard DECSI clients if DECSI does not exist and they have none other options to access credit services they access from it (DECSI)? This leads to the desires to build a reasonable and thoughtful comparison group-the control group.

Despite the strategic limitations recognized, unless Randomized Control Trials (RCTs) experimental arrangements have been largely and thoroughly enforced (e.g. Banerjee, Duflo, Glennerster, Kinnan, 2009; Crépon, Devoto, Duflo, Parienté, 2011; and Karlan \& Zinman, 2008 ) impact assessment based on simple contrasts between micro-finance services participants and nonparticipants are subject to biases from different sources (Pitt and Khandker 1998; Ravallion 2001).

First, bias could arise owing to program arrangement and transpires since micro-finance systems (MFIs) do not randomize over villages to determine and enforce programs. They may choose clients based on attributes unobservable to the analyst. Second, the bias may arise the disposition of individual borrowers to self-select into programs or self-select not to take part at all. To illustrate this, likely applicants themselves can select themselves to apply for a loan if selection into the program is based on unobservable individual characteristics (e.g., entrepreneurial ability) that at the same time affect the impact outcome, attributing observed differences to credit gives biased impact estimates. Third, a source of bias is the difficulty to untangle its impact when microfinances service is rendered intertwined and together with other integrated packages (rural and urban household integrated package in the Ethiopian case). Finally, when most of the residents of the study area are micro-finance clients, the treatment-controlled impact analysis could be suspicious (Berhane, \& Gardebroek, 2011).

However, conforming to Wooldridge (2012), with observational (retrospective) data, it's logical to assume that treatment (i.e. participation in micro-finance) is randomly assigned conditional on observable covariatescommonly termed as 'confoundedness' or perplexed of treatment and selections on observables and/or the exogenous treatment. Further assuming confoundedness of treatment, the next best plausible way out under such a scenario, propensity score and matching methods regression estimations can better address such problems. Since the micro-finance (DECSI) program was in operation since 1997 and there was any repository on baseline data, propensity score and matching methods regression estimations are the merely conceivable alternatives under such schemes.

In such scenarios and in the presence of confoundedness, propensity score weighting and matching techniques identify treatment effect parameters. It must be noted however, that propensity score matching techniques are a better option and seem to work better than other settings of techniques but not a panacea for problems emerged from self-selection methods; endogeneity, exogeniety and reverse causality.

However, since there is an insufficiency of or limited data archives and hence baseline data before and after the intervention records do not exist most times; we opt for with- and without contrasts. Correspondingly, the 
randomized control trial method could not be applied here since the research was carried out recently while the micro-finance scheme was in operation since 1997.

Correspondingly, another key premise is "overlapping," that proclaims the affinity of the covariate distributions for the exposed and controlled subgroups. Propensity score analysis (PSA); a nonparametric approach to reduce model dependence is a dominant technique it balances pre-treatment courts, making the causal effect inference from observational data as reliable as possible Zhang (2017). We derive conventional approaches for determining the average treatment effect on the treated (from cross-sectional settings regarding data format).

\section{Fundamental Concepts: Models, Estimation Procedures of Social Programs Impact Evaluation and Counterfactual Outcomes}

Given that a binary treatment $\mathrm{T}^{3}$-so two results and states of the world, $T=0$ and $T=1$; for each populations unit, corresponding to Neyman-Rubin causal model (for a sequential account see Freedman(2006), each member of the population under the study, labeled $i$, has two values associated with it and two probable outcomes:

$W_{0}$ (the outcome without treatment) and $W_{1}$ the outcome with treatment. $W_{0 i}$ and $W_{1 i}$, which are outcomes that $i$ would display if it did not get the treatment, $T_{i}=0$, and if it got the treatment (exposed) $T_{i}=1$. Since each $i$ is in the exposed group or in the control group; we observe one of $W_{0 i}$ and $W_{1 i}$, yet not both. Notice that $\left(W_{0 i}\right)$ and $\left(W_{1 i}\right)$ can be discrete, continuous, or some mix.

We would like to know the distribution of the distribution over $i$ of the gain from treatment, for a unit $i$, the gain from treatment can be written as

And its mean

If we could observe these gains for a random sample, the problem would be easy: just average the gain across the random sample. The key problem we encounter now is that for each unit we observe $i$, only one of $\left(W_{i 0}\right)$ $\left(W_{i 1}\right)$. It implies that we now have a missing data problem. We will assume a random sample from the population, yet again we do not observe both outcomes as an even cannot be observed in two states of nature simultaneously.

Here, the average treatment effect $(A T E)$ is given by

This the average gain for the randomly selected unit from the population. Besides, another variable of interest is the average treatment effect on the treated (ATT) is the average gain for those who were treated and is denoted by:

$\tau_{\text {att }}=E\left[\left(W_{1}\right)-\left(W_{0}\right) \mid T=1\right]$

Note that with heterogeneous treatment effects, i.e., $\left(W_{i 1}\right)-\left(W_{i 0}\right)$ is not constant. Saying it differently, $\tau_{\text {ate }}$ and $\tau_{\text {att }}$ may be very different. According to Wooldridge (2012) $\tau_{\text {ate }}$ and $\tau_{\text {att }}$ are defined without reference to a model or discussions of the treatment. These definitions hold when whether an assignment is randomized, unconfounded, or endogenous.

How we estimate $\tau_{\text {ate }}$ and $\tau_{\text {att }}$ depends on what we assume about the intervention/treatment assignment.

\footnotetext{
${ }^{3} \mathrm{~T}=$ Treatment or exposed to social programs in this study for instance-treatment is referred as sub population group participating in microfinanceparticularly the poor and poorest of the poor who do not have access to the formal banking services as they cannot fulfil the requirement of the formal banking system that mandatory in order to get credit in the Ethiopian Banking system. Participants in micro finance are loosely defined as microfinance clients and beneficiaries of micro finance credit, saving and other products served to clients in the space of microfinance institutions in Ethiopia in which their core missions, strategies, and ultimate goals are to alleviate poverty though they may somehow differ in tactics, service delivery methods, targets, assessing their overall impacts, ownerships and so forth. Likewise, micro finance institutions (MFIs) are perceived as in/formal banking service systems are provided to unemployed or low-income individuals or groups who otherwise have no other access to financial services. Broadly speaking, the ultimate goals of microfinance is to give low-income people an opportunity to become self-sufficient by providing a way to save money, borrow money and get insurance.
} 
Also, we can define ATEs and TTS conditional on sets of observed covariates. Some approach estimating $\tau_{\text {ate }}$ and $\tau_{\text {att }}$ depend on first estimating conditional average treatment effects.

According we can define to Wooldridge (2012), the average treatment effect in a sample form:

$\tau_{\text {sate }}=N^{-1} \sum_{i=1}^{N} \quad\left[\left(W_{i 1}\right)-\left(W_{i 0}\right)\right]$

Assuming independent, identically distributed observations from the underlying population; we would like to have $\left\{\left(W_{i 0}, W_{i 1}\right): i=1, \ldots, N\right\}$, but we only observe $\left\{\left(T_{i}, W_{i}\right): i=1, \ldots, N\right\}$, where

$W_{i}=\left(1-T_{i}\right) W_{i 0}+T_{i} W_{i 1}=W_{i 0}+T_{i}\left[W_{i 1}-W_{i 0}\right]=W_{i 0}=+T_{i} *$ Gain $_{i}$

The underpinning message from equation (6) above is that random sampling rules out treatment of one unit influencing other units. Hence, stable unit treatment value assumption (SUTVA), is in effect; so one unit's treatment status has no effect on other unit's outcomes. Considering estimation under random assignment and a strong form of random assignment: $\left[W_{0}, W_{1}\right]$ is independent when

$E(W \mid T=1)-E(W \mid T=0)=E\left[W_{1}\right]-E\left[W_{0}\right]=\tau_{\text {ate }}=\tau_{\text {att }}$

And $\mathrm{E}(W \mid T=1) \mathrm{E}(W \mid T=0)$ can be estimated by using sample averages on the two sub-samples.

$$
\hat{\tau_{a t e}}=\overline{W_{1}}-\overline{W_{0}}
$$

In the like manner, to reinforce what we stated in equation (7) above, what we can observe from the data is the difference between the average outcome in the treatments and the average outcome in the controls, or mathematically $\mathrm{E}\left(W_{i} \mid T_{i}=1\right)-\mathrm{E}\left(W_{i} \mid T_{i}=0\right)$. According to Deaton (2010), we can further break this difference up in to

$E\left(W_{i 1} \mid T_{i}=1\right)-E\left(W_{i 0} \mid T_{i}=0\right)=\left[E\left(W_{i 1} \mid T_{i}=1\right)-E\left(W_{i 0} \mid T_{i}=1\right)\right]+\left[E\left(W_{i 0} \mid T_{i}=1\right)-E\left(W_{i 0} \mid T_{i}=0\right)\right]$

As we can deduce it from equation (8) above, the right-hand side of the first square bracket countervail with the first term, in the second square bracket. In contrast, the term in the second bracket is zero by randomization; the non-treatment outcomes are identical considering the expected values of the treatment and the control groups.

Therefore, equation (8) can be expressed as follows;

$E\left(W_{i 1} \mid T_{i}=1\right)-E\left(W_{i 0} \mid T_{i}=0\right)=\left[E\left(W_{i 1} \mid T_{i}=1\right)-E\left(W_{i 0} \mid T_{i}=1\right)\right]$

Hence the difference in the two observable outcomes is the difference between the average treated outcome and the average untreated outcome in the treatment group. The last term on the right side would be unobservable in the absence of randomization. What we are looking for is the average of the difference, instead of the difference of average it present which in the right side of equation (9). Likely enough, the expectation is a linear operator, and therefore, the difference of the average is identical to the average of difference, hence we finally reached at;

$$
E\left(W_{i 1} \mid T_{i}=1\right)-E\left(W_{i 0} \mid T_{i}=0\right)=E\left(W_{i 1}-W_{i 0} \mid T_{i}=1\right)
$$

The difference in means between the treatment and controls is an estimate of the average treatment effect among the treated is an estimate of the average treatment effect for all. This depends on randomization and on the linearity of expectations. The inevitable problem is that if the treatment assignment is not random (program placement or self-selection into the program) and we correlate it with unobserved factors, we will correlate the error term and $\mathrm{T}$ and this will bias the estimate of the program effect. We believe that the success of an impact evaluation depends on identifying a good comparison group, getting rid of the selection bias or accounting for it. The procedure below adopted from Wooldridge (2012) and Deaton (2010), changed and blended when necessary are a mechanism to curb such problems.

The conventional setup of such type of scenario is where there is a pre-treatment period and then an intervention (treatment), in which we expose units to the treatment. Whereas we use the pre-treatment observations as 
SocioEconomic Challenges, Volume 3, Issue 2, 2019

ISSN (print) - 2520-6621, ISSN (online) - 2520-6214

controls to predict treatment assignment.

\section{Confoundedness and Overlap}

To properly arrest this inevitable problem in the impact evaluation of a social program, let's start by defining the counterfactual means as $\mu_{g}=\mathrm{E}\left[W_{g}\right\rfloor$ the expected gain in going form $g-1$ to $g$ is $\mu_{g}-\mu_{g-1}$. It $W_{0}$ is the response under no treatment $\mu_{g}-\mu_{0}$ is the average gain of treatment level $g$ relative to no treatment.

Further assuming that the random assignment, for each unit $i$ we also draw a vector of covariates, $X_{i}$. Let $X$ be the random vector representing the population distribution. The following are the scenarios under this situation:

a) The strongest form of confoundedness: Conditional on $\mathrm{X}$, the counterfactual outcomes are independent of T. Expressly, for units in the subpopulation group designated by $X=x$, assignment is randomized.

b) Unconfoundedness: Conditional on a set of covariates $X$, the pair of counterfactual outcomes,

$\left[W_{0}, W_{1}\right] \perp T \mid X$,

Where the notation " $\perp$ " means 'independent of' and "|" means 'conditional on.' We can also write equation (11) as below based on 'unconfoundedness' and 'ignorability,' as

$D\left[T \mid W_{0}, W_{1}, X\right]=D(T \mid X$,

Where $D(\bullet \mid \bullet)$ stands for conditional distribution.

Wooldridge (2012), discussed "unconfoundedness as a controversial concept that underlines standard regression methods to estimating treatment effect (via a 'kitchen sink' regression that includes the treatment indicator along the controls. Not to mention, a weak version of unconfoundedness-usually termed as unconfoundedness in conditional mean is specified as:

$E\left[W_{g} \mid T, X\right]=E\left[W_{g} \mid X\right], g=0,1$

Wooldridge (2012), argued that unconfoundedness is generally violated if $X$ includes variables that are themselves affected by the social program intervention-i.e., treatment.

Besides, he argued that in some extreme cases where $\left[W_{0}, W_{1}\right]$ is independent of $T$ but $X$ is not dependent of $T$ think of some scenarios like the assignment is being randomized yet $X$ includes a post assignment variable that can be affected by the treatment might reveal that unconfoundedness fails unless:

$E\left[W_{g} \mid X\right]=E\left[W_{g}\right], g=0,1$

A captivating argument that assists an analysis based on unconfoundedness is that the quantities we need to estimate are non-parametrically identified. Conversely, instrumental variable methods, for example, lack the parameters they estimate and impose functional forms and distributional restrictions.

To fix matters, let's consider cases where unconfoundedness hold, but the model limits the information on the domain when choosing microfinance participants. To identify $\tau_{\text {att }}=\left[W_{1}-W_{0} \mid T=1\right]$, can decamp with the weaker unconfoundedness assumption. Under such circumstances,

$W_{0} \perp T \mid X$

Or even the mean version,

$E\left[W_{0} \mid T, X\right]=E\left[W_{0} \mid X\right]$

This allows the unit specific gain, $W_{i 1}-W_{i 0}$, to depend on treatment status $T_{i}$ arbitrarily. 
To shed light the glimpse of overlapping in impact evaluation of social programs, let's pay attention to the following discussion by Woodridge (2012),

For all $X$ in the support $\chi$ of $X$,

$0<P(T=1 \mid X=x)<1$

To state it differently, each unit in the defined population has a chance of being taking part/treatment in microfinance and some chance of not being taking part/no treatment. We know the probability of participation in micro-finance/treatment as a function of $x$ as the propensity score; we designate which as:

$p(x)=P(T=1 \mid X=x)$

Another vital point worth mentioning here, according to Rosenbaum and Rubin (1983);

strong Ignorability = Unconfound edness plus Overlap. For ATT, overlap can be relaxed to

$p(x)<1$ for all $x E X$

We might have $p(x)=0$ because we average only over the treated subpopulation.

\section{Identification of Average Treatment Effects:}

There are two ways to show we identify the treatment effects under unconfoundedness and overlap. First, based on regression functions Define the average treatment effect conditional on $x$ as

$\tau(x)=E\left[W_{1}-W_{0} \mid X=x\right]=\mu_{1}(x)-\mu_{0}(x)$

Where $\mu_{g}(x) \equiv \mathrm{E}\left[W_{g} \mid X=x\right], g=0,1$.

The function $\tau(x)$ is an interesting point as it provides the average treatment effect for different segments of the population expressed by the observables, $X$. By iterated expectations,

$\tau_{\text {ate }}=E\left[W_{1}-W_{0}\right]=E[\tau(X)]=E\left[\mu_{1}(X)-\mu_{0}(X)\right]$

I $\tau_{\text {ate }}$ s identified if $\mu_{0}(\bullet)$ and $\mu_{1}(\bullet)$ are identified by the values of $X$,

because it can be observed a random sample on $X$ and can across its distribution.

Move over $\mu_{0}(\bullet)$ and $\mu_{1}(\bullet)$ are identified under confoundedness and overlap:

$E(W \mid X, T)=(1-T) E\left[W_{0} \mid X, T\right]+T E\left[W_{1} \mid X, T\right]$

$=(1-T) E\left[W_{0} \mid X\right]+T E\left[W_{1} \mid X\right]$

$\equiv(1-T) \mu_{0}(X)+T \mu_{1}(X)$

Where the second equation holds by unconfoundedness. Defining the conditional means of the observed outcomes as

$m_{0}(X)=E(W \mid X, T=0), m_{1}(X)=E(W \mid X, T=1)$

Under overlap, $m_{0}(\bullet)$ and $m_{1}(\bullet)$ are non-parametrically identified on $\chi$ since we have a random sample on $(W, X, T)$. When we add unconfoundedness, we can single out $\mu_{0}(\bullet)$ and $\mu_{1}(\bullet)$ because

$E(W \mid X, T=0)=\mu_{0}(X), E(W \mid X, T=1)=\mu_{1}(X)$

For $A T T$,

$\mathrm{E}\left[W_{1}-W_{0} \mid T\right]=\mathrm{E}\left[\mathrm{E}\left(W_{1}-W_{0} \mid X, T\right) \mid T\right]=\mathrm{E}\left[\mu_{1}(X)-\mu_{0}(X) \mid T\right]$

and we know $\mu_{0}(\bullet)$ and $\mu_{1}$ are identified by unconfoundedness and overlap. In terms of identification of mean 
functions,

$\tau_{\text {ate }}=E\left[m_{1}(X)-m_{0}(X)\right]$

$\tau_{\text {att }}=E\left[m_{1}(X)-m_{0}(X) \mid T=1\right]$

By definition, we can always estimate $\mathrm{E}\left[m_{1}(X) \mid T=1\right]$, and thus, for $\tau_{\text {att }}$, we can get with partial overlap.

We ought to estimate $m_{0}(x)$ for all values of $x$ taken on by the treatment group, which translates in to $p(x)<1$ for all $x E \quad \chi$. Besides, we can also construct identification of $\tau_{\text {ate }}$ and $\tau_{\text {att }}$ using propensity score. According to Wooldridge (2012), assuming unconfoundedness can reveal [Wooldridge (2010, chapter 21)

$E[T W / p(X)]=E\left[W_{1}\right]$

$E[(1-T) W / 1-p(X)]=E\left[W_{0}\right]$

By blending equations (27) and (28)

$\tau_{\text {ate }}=E\left[\frac{T W}{p(X)}-\frac{(1-T) W}{1-p(X)}\right]=E\left\{\frac{[T-p(X)] W}{p(X)[1-p(X)]}\right\}$

We can also show that

$\tau_{\text {att }}=\left\{\frac{[T-p(X)] W}{\rho[1-p(X)]}\right\}$

where $\rho=P(T=1)$ is the unconditional probability of treatment? Here, our need what is $p(x)<1$ because $\tau_{\text {att }}$ is an average effect for those exposed to the treatment/treated by chance. Perhaps the confoundedness and overlap to identify $\tau_{\text {att }}$ are weaker than for $\tau_{\text {ate. }}$

\section{Estimation Mechanisms of Average Treatment Effects}

Whilst we surmise unconfoundedness treatment and overlap, there are three general approaches to estimating the treatment effects:

i. Regression-based methods (on covariate or propensity score)

ii. Propensity score waiting for methods

iii. Matching methods (on covariates or propensity score).

While using these methods that all the methods presented above presume under unconfoundedness and overlap. Even if unconfoundedness holds, overlap could still be weak and pose a problem. Under regularity conditions, estimators are asymptotically efficient and consistent under unconfoundedness and overlap.

\section{Propensity Score Matching (PSM)}

To fix matters short, from the three general approaches to estimating the treatment effects presented above: PSM estimates are reliable if the following assumptions hold: (i) participants and controls have the same distribution of unobserved characteristics; we often refer a failure of this condition to hold to as "selection bias;" (ii) they have the same distribution of observed characteristics; (iii) to both groups; (iv) participants and controls are from the same economic environment; (v) unit homogeneity (no unobserved heterogeneity); and (vi) conditional independence (no reverse causality). This study considers all the assumptions. Assumptions $\mathrm{v}$ and vi are considered by randomization of sample households and control treatment quasi-experiments in the cross-sectional data analysis. The propensity score is defined by Rosenbaum and Rubin (1983) as the conditional probability of receiving a treatment given pre-treatment characteristics.

$p(X) \equiv P\left\{T=\frac{1}{X_{i}}\right\}=E\left\{\frac{T}{X_{i}}\right\}$

Where: $T=0,1$ is the indicator of exposure to treatment. In this study, it is the binary variable of whether a household takes part in micro-finance (take part in micro-finance, $1=y e s ; 0=$ otherwise), and is the vector of 
pre-treatment or time-invariant characteristics. The function $\mathrm{p}(\mathrm{x})$ is the response probability of treatment. Rosenbaum and Rubin (1983) showed that, if participation in micro-finance is random within cells defined by $\mathrm{X}$, it is also random within cells defined by the mono-dimensional variable $\mathrm{p}(\mathrm{X})$. As a result, given a population of units denoted by , if the propensity score $\mathrm{p}(\mathrm{X} \mathrm{i})$ is known; the Average Effect of Treatment on the Treated (ATT) or, with this study, the policy effect of micro-finance as an anti-poverty tool, can be estimated in the same way as in Becker and Ichino (2002) and Ravallion (2001): $\tau \equiv E\left\{W_{1 i}-W_{0 i} / T_{i}=1\right\}$

$\tau=E\left\{E\left\{W_{1 i}-W_{0 i} / T=1, p\left(X_{i}\right)\right\}\right\}=E\left\{E\left\{W_{1 i} / T_{i}=1, p\left(X_{i}\right)\right\}-E\left\{W_{0 i} / T=0, p\left(X_{i}\right)\right\} / T_{i}=1\right\}$

Where i denotes the ith household, $Y_{1 i}$ the impact indicators (vector of households' per capita yearly expenditures or asset holdings) over the distribution of $\left(p\left(X_{i}\right) / T_{i}=1\right)$ and $Y_{0 i}$ the potential outcomes in the counterfactual situation of no participation. Thus, the first line of the equation states that the policy effect is defined as the expectation of the difference of the impact indicators of the $i^{\text {th }}$ household with participation in microfinance and that for the same household in the counterfactual situation in which it would not have taken part in micro-finance. The second line is the same as the first line, except that we define the expected policy effect over the distribution of the propensity score. The last line is the policy effect as an expected difference of the expected impact and poverty status indicators for the $i$-th household with participation in micro-finance, given the distribution of the probability of participation in micro-finance and that for the same household without participation. We require the following two hypotheses to derive equations (31) and (32).

Lemma 1 Balancing of pre-treatment variables, given the propensity score: if $p(X)$ is the propensity score, then

$T \perp X \mid p(X)$

This implies that, given a specific probability of participation in micro-finance, a vector of household characteristics $X_{i}$ is orthogonal to (or uncorrelated to) participation.

Lemma 2. Unconfoundedness, given the propensity score:

If the treatment (or whether a household takes part in microfinance) is unconfounded,

then, assignment to treatment is unconfounded, given the propensity score, i.e.,

$W_{1 i} W_{0 i} \perp T \mid p(X)$

The latter implies that, given a propensity score, the impactor poverty status indicators are uncorrelated to participation in micro-finance. If we satisfy the above Lemma theorems, the procedures can estimate microfinance's impact discussed by (Becker and Ichino, 2002).

Finally, we estimate the probit model:

$p\left\{T_{i}=1 \mid X_{i}\right\}=\varphi\left(h\left(X_{i}\right)\right)$

To put it differently, Wooldridge (2012), argued that key results of the Rosenbaum and Rubin (1983); given that unconfoundedness conditional on $X$, unconfoundedness holds true if we condition only on $p(X)$ : $\left[W_{0}, W_{1}\right] \perp T \mid p(X)$ and hence $E[W \mid p(X), T=1]=E\left[W_{1} \mid p(X)\right]$.

After estimating $p(\bullet)$ by logit or probit (we used probit binary model in the participation equation in this study), we estimate $E[W \mid p(X), T=0]$ and $E[W \mid p(X), T=1]$ using each sub-sample. For $\tau_{\text {ate }}^{\wedge}$, use the average difference in fitted values.

In the linear outcome model, $\widehat{\tau_{\text {ate }}}$ can be computed as the coefficient $T_{i}$ from the pooled regression given by:

$W_{i}$ on $1, T_{i}, \hat{p}\left(X_{i}\right), \quad T_{i} \bullet\left[\hat{p}\left(X_{i}\right)-\hat{\mu} \hat{p}\right], \quad i=1, \ldots, N$

Where $\hat{\mu} \hat{p}=N^{-1} \sum_{i=1}^{N} p\left(\hat{X}_{i}\right)$

The inference ignoring estimation of $p(\bullet)$ is conservative. We applied the bootstrap to get smaller and valid 
standard errors. The functions of log-odds ratio such as equation (38) we can use below for producing a better fit.

$$
\hat{r}_{i} \equiv \log \left[\frac{p\left(\hat{X}_{i}\right)}{1-p\left(\hat{X}_{i}\right)}\right]
$$

To sum up, to produce reliable methods for regressions, estimations and produce best matches of covariate estimations propensity scores; we combined various regressions and estimation techniques such as Propensity Score weighting, matching on the propensity score, radius matching techniques, nearest neighbor matching methods, stratified matching method and based on radius matching methods.

\section{Heckman's Selection Model}

Alternatively, we used a Heckman version Treatment Effect Model with a similar inference to verify the consistency of the results got using propensity score matching methods by picking several variables as a case study. More explicitly, we adopt the selection model stated in (Greene, 2003, p. 764)

$$
T_{i}^{*}=\gamma X_{i}+\varepsilon_{i}
$$

and

$T_{i}^{*}=1 \rightleftarrows \operatorname{IfT}_{i}^{*}=\gamma X_{i}+\varepsilon_{i}>0$

$T_{i}^{*}=0$, Otherwise

Where $P\left\{T_{i}=1 \mid X_{i}\right\}=\left(\frac{\gamma X_{i}}{\delta}\right)$

$$
P\left\{T_{i}=0 \mid X_{i}\right\}=1-\Phi\left(\frac{\gamma X_{i}}{\delta}\right)
$$

$\stackrel{*}{T_{i}}$ is the latent variable. In our case, $T_{i}$ takes 1 if the households take part in micro-finance and 0 if not; $X_{i}$ is a pre-treatment variable that determines participation, while $\Phi$ stands for the normal cumulative distribution.

We specify the linear outcome regression model in the second stage below to study the impact indicators and examine poverty determinants:

$W_{i}=\beta^{\prime} Z_{i}+\omega T_{i}+\eta_{i}$

$\left(\eta_{i} \varepsilon_{i}\right) \sim$ bivariate normal $\left[0,0,1, \sigma_{\eta}, \rho\right]$

where $\omega$ is the average benefit of taking part in micro-finance $Z_{i}$ is a vector of household characteristics.

Manipulating the formula for the joint density of bivariate normally distributed variables,

the expected impact of micro-finance on poverty indicators of clients is given by

$$
E\left[W_{i} \mid T_{i}=1\right]=\beta Z_{i}+T_{i} \omega+E\left[\eta_{i} \mid T_{i}=1\right]=\beta Z_{i}+D_{i} \omega+\rho \delta_{\eta} \frac{\varphi(\gamma X / \delta)}{\Phi(\gamma X / \delta)}
$$

Where $\phi$ is the standard normal density function, and we call the ratio of $\phi$ and $\Phi$ the Inverse Mills Ratio or (Heckman's lambda), given the expected impact and poverty indicators for non-participants in microfinance.

The expected effect of poverty reduction associated with micro-finance is obtained by borrowing the following model from Greene (Greene, 2003, p. 765).

$$
E\left[W_{i} \mid T_{i}=1\right]-E\left[W_{i} \mid T_{i}=0\right]=\omega+\rho \delta_{\eta} \frac{\varphi\left({ }^{\gamma X} / \delta\right)}{\Phi\left({ }^{\gamma X} / \delta\right)\left[1-\Phi\left({ }^{\gamma X} / \delta\right)\right]}
$$

To sum up, we adopted a changed version of the FGT (1984) poverty analysis approach to examine the status 
of poverty profiles in the study area. In order to comprehensively control various pitfall in the impact analysis approach, we adopted the treatment effect model as discussed by Wooldridge (2012) and Deaton (2010) and we used the various matching methods under the PSM. Finally, to corroborate and verify the estimation procedures followed, we used the Heckman's Selection Model.

\section{Estimation Results and Discussions}

\section{The extent of poverty and estimation results of its measures}

Good harvests and relatively stable prices characterized the survey period in the first year (2008) and bad harvests (drought) and distorted prices in the second year (2010). To rein in the price climb, we made price adjustments for both datasets, with the 2006 price as the base, as used by Fredu (2009) for computing food and total poverty lines.

We used the consumer price index (CPI) for food and non-food items from the CSA and CPI reports (2009). Thus, as much as possible, we tried to minimize the impact of inflation on a poverty line computed several years ago. After making price adjustments for both years (2008 and 2010), we got (1192.2 ETB and 1278 ETB) and (1592 ETB and 1718.4 ETB) as the food and total poverty lines in 2008 and 2010, respectively. We strongly believe that using these poverty lines is more appropriate than the national poverty lines, as they are based on the particular study area. As inferred from Table 1 below, both extreme poverty (measured using the food poverty line) and moderate poverty (measured using the total poverty line we adopted) remained the same in 2008 and 2010.

In addition, as it can be seen in Table 1, poverty measures, such as poverty incidence, showed infinitesimal changes in 2008 and 2010, while the depth of poverty increased from 12 to 10.5 percent in 2008 to 19 and 14.5 percent in 2010, and the severity of poverty increased from 6.9 and 3.5 percent in 2007 in extreme (food) poverty and moderate (total) poverty, respectively, to 10.3 and 6.8 in 2010, respectively, for the total sample. For detailed information on this issue, please see Table-1 below.

\section{Results of propensity score matching on participation in micro-finance (determinants: dep variable)}

Estimation results of the Probit model (micro-finance participation equation) in Table-2 (appendix) are insightful in the case for the entire households where the dependent variable is participation in micro-finance. Compared to young and old aged headed households, middle age headed households are more likely to a participant in micro-finance; save for the negative coefficient of age square suggests the nonlinear effect, which is significant at $10 \%$ significance level. Households with a large family size are more likely to take part in micro-finance significant at a $1 \%$ significance level. This is plausible since a family with excess labor force may take credit and take part in farm or non-farm activities to support their life and make a living. Besides this, per capita land and its logarithm are significant at (5\% level of significance) and we can infer from table2 that households with a larger per capita land (measured in hectares) take part more.

The coefficient estimates of area dummies in all the three sites, Arato, Rubafeleg, and Tsenkanet, are positive and highly significant. Arato is significant at the $1 \%$ level of significance, and the other two are significant at the $5 \%$ level of significance. Their interpretation considers Siye as a base area dummy, and we can conclude from Table-2 that residents of these areas have a higher probability to take part in micro finances compared with the residents of Siye.

\section{Results of propensity score matching: effects of access to micro-finance services (DECSI) on Poverty (of DESCI Clients)}

Table-3 below shows the results based on whether a household has ever taken a loan from DECSI. The null hypothesis $\left(\mathrm{H}_{0}\right)$ is participation in micro-finance has a known impact on a household's non-food expenditure indicators and/or on baskets of non-food goods and services (such as medical, education and education materials, social occasions and clothing and personal care). Considering per capita expenditure on baskets of nonfood items, there is no significant difference between DECSI clients and non-clients.

Here, we focused on household monthly per capita expenditures on non-food baskets of goods and services (medical, education and education materials, social occasions, clothing, and personal care).

As seen from table 3 below, household per capita expenditure on children's education materials imputed to be 1 percent significance level in the stratified and radius matching methods. Besides, the same indicator is 
significant at 5 percent level of significance in the kernel matching method. We find household per capita to be significant at 5 percent level of significance in the nearest neighbor matching method. We find all other categories to be insignificant.

In the literature, we commonly define expenditure on children's education as expenditures on human capital development. All the results use bootstrapped standard errors. We are interested in the columns labeled as 'Average treatment effect on Impact Indicators' and the-ratio'. Regarding expenditures on schooling, participation in micro-finance has significant effects, allowing parents to spend more on items (school materials) such as books, pens.

This is consistent with the findings of Cowen and Boudreaux (2009) who reported that loans were used to pay for a child's doctor visit in Hyderabad, India and many borrowers in Tanzania revealed that $60 \%$ of their loan is utilized to send school-age children to while the reaming 40 percent was used for investments. While we spent 30 percent of the borrowed micro-credits on some forms of consumption.

We can deduce it; therefore, that we rejected the null hypothesis since household's per capita non-food expenditures on children's education is significant in the average treatment effect on the treated radius (Attr) and stratification (Atts) matching method at (1\%) and the kernel (Attk) weighted matching method (at 5\%) level of significance, respectively. It implies that households with access to micro-finance have a better chance of spending on children's education materials which are likely to improve the next generation living standard by investing in children of the future generation and human capital. We should note, however, that we could not reject the null hypothesis in all the other cases.

\section{Household per capita productive and fixed (assets with and without housing) ownership}

This section elaborates estimation results of ATT using the same method as above, and it displays microfinance/DECSI's impact on per capita household productive and fixed assets (with and without a house) ownership in the current value of housing in ETB and household per capita productive assets.

By the same token, the null hypothesis $\left(\mathrm{H}_{0}\right)$ there is no significant difference in the household per capita fixed and productive asset ownership between DECSI clients and non-clients.

Table 4 presents the results of matching estimators, we base which on equations (1) to (38). It shows the results based on whether a household has ever taken a loan from DECSI.

Considering household per capita fixed assets, including house ownership, ATT appears to have a significant impact (at 10 percent level of significance) in the nearest neighbor matching method. Whereas, we find per capita fixed assets (excluding house to be significant at a 10 percent significance level in the radius and nearest neighbor matching methods.

Table 4 below illustrates that we find household per capita to be significant (at 10 percent and 5 percent significance levels) in the stratifies and nearest neighbor matching methods, respectively.

To sum up, The logical conclusion from this analysis is that we reject the null hypothesis as there is a statistically significant impact difference (at 10\% significance level) considering household per capita fixed assets ownership including house and household per capita productive assets ownership in the radius and nearest neighbor matching method and conclude that DECSI clients seemed to have more per capita asset ownership without house and per capita productive assets as compared with non-clients.

The plausible prediction considering household per capita fixed assets ownership (including and excluding house) is that; it is likely that DECSI clients may own improved/better fixed and productive assets as compared with non-client counterparts. Moving on, there is a significant difference (10\% and 5\% level of significance) in micro-finance clients and non-clients in the ownership of household productive assets in the stratified and nearest neighbor matching methods, respectively. The null hypothesis stated as there is no significant difference among micro-finance participants and nonparticipants in the ownership of productive household assets are therefore rejected. The implication is that it is likely to observe the difference in household productivity owing to the difference in the ownership of household productive and non-productive assets.

\section{ATT estimation results for household per capita (food and total expenditures),} and total poverty severity 
Table-5 displays the results of matching estimators based on equations (1) and (38). And, Table-5 shows the results, we base which on whether a household has ever taken a loan from DECSI.

Similarly, the next logical null hypothesis $\left(\mathrm{H}_{0}\right)$ there is no significant difference in the household per capita expenditure on food, non-food and poverty severity between DECSI clients and non-clients.

We are interested in household basic welfare indicators, such as household monthly per capita expenditures on food and non-food items and total poverty severity. All the results use bootstrapped standard errors. We are interested in columns labeled, 'Average treatment Effect on Impact Indicators/ATT/' and t-value. As seen from we find Table-5, ATTs to be significant (at the 5\% level of significance) in stratification matching in all cases. However, ATTs are insignificant in all other propensity score-matching methods.

Considering household per capita expenditure on food, food \& non-food (total) and poverty severity, household per capita expenditure on food is significant (at 5 percent significance level) in the stratified matching method.

Correspondingly, household per capita expenditure on total (food and non-food) items is significant at 5 percent level of significance of the stratified matching method. Uniquely, household square poverty gap ratio (poverty severity) is sought to be significant at 5 percent level of significance in the stratified matching method. Here also, we reject the null hypothesis focusing especially on the indicators and matching methods discussed above.

This does not mean participation in micro-finance has a statistically significant effect on poverty and is an effective tool in fighting poverty. Because, micro-finance client households, though they have access to credit, may become poorer and poorer especially when there are loan diversions, production failure, and other social and natural shocks. This is what we learned in some focused group discussions we held with clients.

Now, we ask whether micro-finance and the DECSI Credit and Saving Microfinance Institution are hitting their targets in lifting the poor out of poverty. In line with the results presented above, we claim that the impacts on the basic welfare indicators are only significant in one of the matching methods and hence difficult to make a consistent general conclusion.

\section{ATT treatment effects model estimation results of household expenditures}

Table 6 shows the first stage: Whether a household has ever taken any loans from DECSI in both household food and total monthly expenditures. We are particularly interested in the second column's first coefficients and the fourth column's second coefficients (coefficients for household total and food expenditures) and their respective t-ratios.

The treatment effect model, by controlling part of the selection bias because of unobserved household-specific endogeneity/omission variable bias, it minimizes the bias that may creep in during impact analysis.

Estimation results of this model in Table 6 have the expected signs and sizes. A household with a middleaged head has significant coefficient estimates with nonlinear effects (at $10 \%$ level of significance). Other participation explanatory variables are similarly significant in this case, with some differences.

The Inverse Mills ratio is insignificant, and we have no statistical reason to reject the null hypothesis that claims that the coefficient of Heckman's lambda is zero. We conclude that the model is linear, and those linear regressions are sound for household per capita food and total monthly expenditures. The key variable of interest-participation in micro-finance institutions-remains significant in both cases.

Perhaps we could link the existence of DECSI to increased productive assets ownership that may stimulate agricultural productivity, and its positive impact on putting children to school and improved access to health services.

However, assessing these momentary impacts against DECSI broad objectives; even if the ultimate objectives of DECSI programs are to reduce poverty via improving the economic opportunities and outcomes and the living standards of the low-income and poorest people based on voluntary participation, although there were some momentary impacts, poverty was rampant in the study area, despite micro-finance programs.

DECSI is making clients' lives better in the study area in the short run. But mostly, it is not pulling them out of poverty. It is very rare to find entrepreneurs who start with these tiny loans and graduate to run commercial 
SocioEconomic Challenges, Volume 3, Issue 2, 2019

empires.

\section{Conclusions and recommendations}

\section{Conclusions of the study}

Using the survey data set, first, we estimated propensity score matching for participation in micro-finance and several pre-treatment variables. We then matched clients and non-clients based on these variables. Next, we estimated the average treatment effect, considering participation in micro-finance as a treatment and participants as the treated group. Finally, we used different matching methods to establish the robustness of the used methods.

Of the non-food baskets of good and service, we considered, we find household expenditure on children's education to be statistically significant for micro-finance participants as compared with non-participants. We find participant household expenditure on fixed assets, productive assets, on food and poverty to be significant at least in one of the matching methods.

Estimation results show that ATTS is not significant for expenditures on medical and personal care. ATT does not appear to be significant for expenditures related to social occasions. Educational expenditures in the above analysis refer to expenditures on the educational items listed. However, education in Ethiopia, particularly in rural areas, is public, and there are no education fees.

Most of the sample considered for this study took part in micro-credit or micro-finance, they did not take part in non-farm activities, and the majority did not have SMMEs when we assessed the scenarios before and after taking part in micro-credit. We suspect that micro-finance does not have significant power to promote microenterprise and entrepreneurship, even though reported that NFEs in rural economies are important, as they are Midland contributors to household income, and their importance has broadened.

The above results show that the impact of micro-finance on surveyed households' poverty indicators was insignificant. However, micro-finance may help households just to survive in times of shock and vulnerability, besides having momentary impacts on productive household assets; the migration and sale of draft animals may prevent households from loss of human capital when facing idiosyncratic shocks.

Now, we ask whether micro-finance and the DECSI Credit and Saving Microfinance Institution are hitting their targets. Given the results presented above, we argue that the impacts on the basic welfare indicators are insignificant according to both the descriptive statistics and in the propensity score-matching methods, except stratification matching.

Our view is in line with those who argue that micro-finance keeps borrowers from even greater catastrophes, but only rarely does it enable them to climb out of poverty. We do not consider micro-credit as a panacea to all multiple overlapping deprivation and poverty experiencing by poor people. Even though micro-finance helps the poor to tread water and just keeps them from drowning, however, we should not expect micro-credit alone to help get the poor out of poverty.

Our estimation results reveal that micro-finance institutions in the study area are more interested in making profits and less interested in helping the poor. In effect, there seem a misunderstanding of the philosophy behind micro-finance and its practical applications on the ground. We claim that the design and implementation of micro-finance institutions follow the same rationale as failed programs for small farmers in the past.

Weak or insignificant effects for the total sample do not mean that micro-finance is useless; it can be a means for dissipating the meager capital of developing countries such as Ethiopia and rescuing the poorest from dying of starvation and from the social disorder that could have been created in its absence. Its importance should not be judged narrowly.

Even if the ultimate objectives of DECSI programs are to reduce poverty via improving the economic situation of the low-income and poorest people based on voluntary participation, although there were some momentary impacts, poverty was rampant in the study area, despite micro-finance programs.

\section{Recommendations}

Research findings and focus group discussions with survey households led us to the following recommendations:

1. Identifying the impact of micro-finance in the face of multifaceted development programs is very difficult, 
and surveys on such issues should be integrated with climate data, farmers' preferences, livestock species, and the availability of sufficient grazing areas. We recommend harmony with other development packages.

2. The insignificant impact of micro-finance on the primary household poverty status indicators needs special focus. The supply side (DECSI) ought to make sure that loans match the needs and preferences of clients. We recommend a series of activities, such as training and follow-ups (before, during and after). Revising policies such as increasing loan amounts and lengthening terms of loans, reducing the continuously swelling interest rates (that consume any returns to clients), increasing interest rates for depositors to instigate savings habits and, thus, capital accumulation, diversifying loan packages and ranges, providing special loans for human capital development, encouraging participation of clients and minimizing the role of local administrators are recommended.

3. We should seriously consider innovative modalities of loan provision, product diversification, capacitating clients on loan utilization, and production supervision and support by MFI designers and implementers.

4. As huge amounts of capital are channeled to enable micro-finance institutions by reducing investments in other productive assets, designers and implementers in this sector should rethink and revisit the gap between theory and practice on the ground.

5. DESCI should give a well-integrated, coordinated, and planned training on Business Development Services, product development and diversification, market penetration and sustainability/survivable of the micro and small enterprises.

\section{References}

1. Armendáriz de Aghion, B., \& Morduch, J. (2005). The Economics of Microfinance MIT Press. Cambridge, Massachusetts.

2. Banerjee, A., Duflo, E., Glennerster, R., \& Kinnan, C. (2015). The miracle of microfinance? Evidence from a randomized evaluation. American Economic Journal: Applied Economics, 7(1), 22-53.

3. Becker, S. and Ichino, A. (2002).Estimation of average treatment effects based on propensity scores. The Stata Journal 2 (4), 358-377.

4. Berhane, G., \& Gardebroek, C. (2011). Does microfinance reduce rural poverty? Evidence based on household panel data from northern Ethiopia. American Journal of Agricultural Economics, 93(1), 43-55.

5. Boudreaux, K.C. and Cowen, T. (2009) 'The micro magic of microcredit', The Wilson Quarterly, 32 (1), 27-31.

6. Cheston, S., \& Reed, L. (1999). Measuring transformation: assessing and improving the impact of microcredit. Journal of Microfinance/ESR Review, 1(1), 3.

7. Christen, R. P. (2001). Commercialization and Mission Drift: The transformation of Microfinance in Latina America, occasional paper, $\mathrm{n} 5$.

8. Crépon, B., Devoto, F., Duflo, E., \& Parienté, W. (2015). Estimating the impact of microcredit on those who take it up: Evidence from a randomized experiment in Morocco. American Economic Journal: Applied Economics, 7(1), 123-50.

9. Datar, S. M., Epstein, M. J., \& Yuthas, K. (2008). In microfinance, clients must come first. Stanford Social Innovation Review, 6(1), 38-45.

10. Deaton, A. (2010). Instruments, randomization, and learning about development. Journal of economic literature, 48(2), 424-55.

11. Foster, J., \& Greer, J. (1984). E. Thorbecke (1984), A class of decomposable poverty measures. Econometrica, 52(3), 761-766.

12. Freedman, D. A. (2006). Statistical models for causation: what inferential leverage do they provide? Evaluation review, 30(6), 691-713.

13. González Vega, C. (1998). Microfinance: broader achievements and new challenges.

14. Haggblade, S., Hazell, P., \& Reardon, T. (2010). The rural non-farm economy: Prospects for growth and poverty reduction. World Development, 38(10), 1429-1441.

15. Heckman, J. J. (1979). Sample selection bias as a specification error. Econometrica: Journal of the econometric society, 153-161.

16. Julien, K. (2009). A look at interest rates in microfinance. New York: New School University.

17. Kar, A. K. (2013). Mission drift in microfinance: are the concerns really worrying? Recent cross-country results. International Review of Applied Economics, 27(1), 44-60. 
18. Karlan, D. S., \& Zinman, J. (2008). Credit elasticities in less-developed economies: Implications for microfinance. American Economic Review, 98(3), 1040-68.

19. Khandker, S. (2001, February). Does micro-finance really benefit the poor? Evidence from Bangladesh. In Asia and Pacific Forum on Poverty: Reforming Policies and Institutions for Poverty Reduction (Vol. 14).

20. Khandker, S. R. (2005). Microfinance and poverty: Evidence using panel data from Bangladesh. The World Bank Economic Review, 19(2), 263-286.

21. Kondo, T., Orbeta Jr, A., Dingcong, C., \& Infantado, C. (2008). Impact of microfinance on rural households in the Philippines. IDS bulletin, 39(1), 51-70.

22. Roodman, D., \& Morduch, J. (2009). The impact of microfinance on the poor in Bangladesh: revisiting the evidence. Center for Global Development (CGD) Working Paper, 174.

23. Morduch, J. (1998). Does microfinance really help the poor?: New evidence from flagship programs in Bangladesh. Research Program in Development Studies, Woodrow School of Public and International Affairs.

24. Morduch, J. (1999a). The role of subsidies in microfinance: evidence from the Grameen Bank. Journal of development economics, 60(1), 229-248.

25. Morduch, J. (1999b). The microfinance promise. Journal of economic literature, 37(4), 1569-1614.

26. Morduch, J. (2000). The microfinance schism. World development, 28(4), 617-629.

27. Morduch, J., \& Johnston, J. (2007a). The unbanked: evidence from Indonesia. Financial access institute (FAI), NYU Wagner Graduate School of Public Service, March.

28. Morduch, J. (2007b). Smart subsidies. In Microfinance and Public Policy (pp. 72-85). Palgrave Macmillan, London.

29. Nega, F. (2008). Poverty, asset accumulation, household livelihood and interaction with local institutions in northern Ethiopia (Doctoral dissertation, Katholieke Universiteit Leuven).

30. Olivares-Polanco, F. (2005). Commercializing microfinance and deepening outreach? Empirical evidence from Latin America. Journal of Microfinance/ESR Review, 7(2), 5.

31. Ravallion, M. (2001). The mystery of the vanishing benefits: An introduction to impact evaluation. the world bank economic review, 15(1), 115-140.

32. Rhyne, E. (1998). The yin and yang of microfinance: Reaching the poor and sustainability. MicroBanking Bulletin, 2(1), 6-8.

33. Rosenbaum, P. R., \& Rubin, D. B. (1983). The central role of the propensity score in observational studies for causal effects. Biometrika, 70(1), 41-55.

34. Tesfay, G. B., \& Gardebroek, C. (2009). Does microfinance reduce rural poverty? Evidence based on household panel data from Tigray, northern Ethiopia.

35. Verbeek, M. (2008). A guide to modern econometrics. John Wiley \& Sons.

36. Weldeslassie, H.A. (2017). Does Microfinance Help to Reduce Poverty in Ethiopia? Propensity Score Matching Impact Analysis. Enterprise Development \& Microfinance 28(4), 255-283. http://10.0.13.34/17551986.2017.HAW\%0Ahttp://search.ebscohost.com/login.aspx ?direct=true \&db=bth\&AN=127504364\&site=e host-live\&authtype=ip, uid.

37. Woldehanna, T. (2005). The impact of Debedit Credit and Savings Institution (DECSI) on Poverty Reduction and Community Development. In Proceedings of the International Conference on Microfinance Development in Ethiopia: Impact and Systainability of MIFs, Addis Ababa, Ethiopia, 2005 (pp. 236-269).

38. Waller, G. M., \& Woodworth, W. (2001). Microcredit as a grass-roots policy for international development. Policy Studies Journal, 29(2), 267-282.

39. Woller, G. M., Dunford, C., \& Woodworth, W. (1999). Where to microfinance. International Journal of Economic Development, 1(1), 29-64.

40. Wooldridge, J. M. (2010). Econometric analysis of cross section and panel data. MIT press.

41. Wooldridge, J. (2012, January). Treatment effect estimation with unconfounded assignment. In American Accounting Association/Financial Accounting and Reporting Section Workshop.

42. Zewde, Z. N. (2008). Microfinance loan delivery, utilization and impact: with specific reference to Tigray, northern Ethiopia. 
Table 1. Estimation results for several poverty measures

\begin{tabular}{|c|c|c|c|c|c|c|c|c|c|c|c|c|}
\hline \multicolumn{9}{|c|}{2009} & \multicolumn{4}{|c|}{2007} \\
\hline Pov. & \multicolumn{2}{|c|}{ Total Sample } & \multicolumn{2}{|c|}{ Borrowers } & \multicolumn{2}{|c|}{ Non-borrowers } & \multicolumn{2}{|c|}{ Total Sample } & \multicolumn{2}{|c|}{ Borrowers } & \multicolumn{2}{|c|}{ Non-borrowers } \\
\hline \multicolumn{13}{|c|}{ Measure } \\
\hline & Food & Total & Food & Total & Food & Total & Food & Total & Food & Total & Food & Total \\
\hline & Pov. & Pov. & Pov. & Pov. & Pov. & Pov. & Pov. & Pov. & Pov. & Pov. & Pov. & Pov. \\
\hline Head & 0.5306 & 0.4294 & 0.5770 & 0.4632 & 0.4190 & 0.3409 & 0.5203 & 0.4178 & 0.5367 & 0.4515 & 0.5224 & 0.4627 \\
\hline Count & $(0.0276)$ & $(0.0278)$ & $(0.0320)$ & $(0.0324)$ & $(0.0527)$ & $(0.0508)$ & $(0.0294)$ & $(0.0273)$ & $(0.0310)$ & $(0.0309)$ & $(0.0615)$ & $(0.0614)$ \\
\hline \multicolumn{13}{|l|}{ Ratio } \\
\hline Pov. & 0.1961 & 0.1446 & 0.2123 & 0.1526 & 0.1615 & 0.1230 & 0.1238 & 0.1053 & 0.1643 & 0.099 & 0.1822 & 0.1341 \\
\hline $\begin{array}{l}\text { Gap } \\
\text { Ratio }\end{array}$ & $(0.0141)$ & $(0.0121)$ & $(0.0165)$ & $(0.0138)$ & $(0.0279)$ & $(0.0247)$ & $(0.0104)$ & $(0.0106)$ & $(0.0127)$ & $(0.0097)$ & $(0.0291)$ & $(0.0258)$ \\
\hline $\mathrm{R}^{2}$ & 0.1026 & 0.0683 & 0.1094 & 0.0685 & 0.0939 & 0.0673 & 0.0697 & 0.0379 & 0.1033 & 0.0348 & 0.0913 & 0.0617 \\
\hline Pov. & $(0.0102)$ & $(0.0053)$ & $(0.0115)$ & $(0.0082)$ & $(0.0235)$ & $(0.0204)$ & $(0.0073)$ & $(0.0046)$ & $(0.0091)$ & $(0.0048)$ & $(0.0185)$ & $(0.0180)$ \\
\hline $\begin{array}{l}\text { Gap } \\
\text { Ratio }\end{array}$ & & & & & & & & & & & & \\
\hline
\end{tabular}

Notes: Results in parentheses are standard errors.

Table 2. Probit estimates for the determinants of participation in micro finance

\begin{tabular}{|c|c|c|c|}
\hline Participation in microfinance & Coefficients & $\mathrm{Z}$ & $\begin{array}{l}\text { Marginal effects after probit } \\
(\mathrm{mfx})\end{array}$ \\
\hline \multicolumn{4}{|c|}{ Household's Demographic Characteristics } \\
\hline Household head age & .072 & $1.93 *$ & 0.0218 \\
\hline Household head age square & -.0007 & $-2.04 * *$ & -0.0002 \\
\hline Household family size & .1783 & $3.29 * * *$ & 0.054 \\
\hline Work force & .3469 & 0.91 & 0.105 \\
\hline \multicolumn{4}{|c|}{ Household ownership } \\
\hline Per capita land & .5394 & $2.85 * *$ & 0.163 \\
\hline per capita land(Log) & -.4913 & $-2.28 * *$ & -0.149 \\
\hline \multicolumn{4}{|c|}{ Location Dummies } \\
\hline Rubafeleg & .7810 & $2.46^{* *}$ & 0.202 \\
\hline Arato & .9768 & $4.08 * * *$ & 0.238 \\
\hline Tsenkanet & .6460 & $2.45 * *$ & 0.173 \\
\hline Constant & -3.360 & $-2.50 * *$ & - \\
\hline Number of obs $=361$ & \multirow{2}{*}{\multicolumn{3}{|c|}{$\mathrm{y}=\operatorname{Pr}($ participation in $\mathrm{mf})($ predict $)=.771$}} \\
\hline LR $\operatorname{chi} 2(16)=70.76 * * *$ & & & \\
\hline \multicolumn{4}{|l|}{ Prob $>$ chi $2=0.0000$} \\
\hline Log likelihood $=-174.705$ & \multicolumn{3}{|c|}{ Pseudo R2 $=0.1684$} \\
\hline
\end{tabular}

Notes: $* * *=$ significant at the $1 \%$ level; $* *=$ significant at the $5 \%$ level; and $*=$ significant at the $10 \%$ level.

Table 3. Estimation of ATT Using Propensity Score Matching

\begin{tabular}{|c|c|c|c|c|c|}
\hline \multicolumn{6}{|c|}{ Dep Variable: Various Investments on Human Capital and Social Occasions Indicators } \\
\hline \multirow{2}{*}{ Impact indicators } & \multirow{2}{*}{$\begin{array}{c}\text { Matching } \\
\text { methods }\end{array}$} & \multirow{2}{*}{$\begin{array}{l}\text { DECSI } \\
\text { Clients }\end{array}$} & \multicolumn{3}{|c|}{ DECSI } \\
\hline & & & Non-Clients & ATT & t-ratio \\
\hline \multirow{4}{*}{$\begin{array}{l}\text { Household per capita medical } \\
\text { expenditures }\end{array}$} & Atts & 264 & 107 & -61.8 & -1.52 \\
\hline & Attr & 264 & 105 & -90.7 & -1.31 \\
\hline & Attnd & 264 & 103 & -187.8 & $-1.71 *$ \\
\hline & Attk & 264 & 106 & -131.1 & -1.5 \\
\hline \multirow{4}{*}{$\begin{array}{l}\text { Per capita expenditures on children's } \\
\text { education materials }\end{array}$} & Atts & 264 & 108 & 115.6 & $5.9 * * *$ \\
\hline & Attr & 264 & 103 & 94.3 & $4.4 * * *$ \\
\hline & Attnd & 264 & 102 & 33.3 & 0.93 \\
\hline & Attk & 264 & 109 & 69.01 & $2.7 * *$ \\
\hline
\end{tabular}


Table 3 (cont.). Estimation of ATT Using Propensity Score Matching

\begin{tabular}{|c|c|c|c|c|c|}
\hline \multicolumn{6}{|c|}{ Dep Variable: Various Investments on Human Capital and Social Occasions Indicators } \\
\hline \multirow{2}{*}{ Impact indicators } & \multirow{2}{*}{$\begin{array}{c}\text { Matching } \\
\text { methods }\end{array}$} & \multirow{2}{*}{$\begin{array}{l}\text { DECSI } \\
\text { Clients }\end{array}$} & \multicolumn{3}{|c|}{ DECSI } \\
\hline & & & Non-Clients & ATT & t-ratio \\
\hline \multirow{4}{*}{$\begin{array}{l}\text { Per capita expenditures on social occa- } \\
\text { sions }\end{array}$} & Atts & 264 & 106 & 74.2 & 0.70 \\
\hline & Attr & 264 & 108 & 44.9 & 0.43 \\
\hline & Attnd & 264 & 103 & 3.03 & 0.14 \\
\hline & Attk & 264 & 109 & 18.5 & 0.14 \\
\hline \multirow{4}{*}{$\begin{array}{l}\text { Per capita expenditures on closing and } \\
\text { personal items }\end{array}$} & Atts & 264 & 108 & 40.6 & 0.91 \\
\hline & Attr & 264 & 107 & 11.2 & 0.15 \\
\hline & Attnd & 264 & 106 & -17.6 & -0.14 \\
\hline & Attk & 264 & 108 & -48.9 & -0.37 \\
\hline
\end{tabular}

Notes:*** = significant at $1 \%$ level; $* *=$ significant at $5 \%$ level; and $*=$ significant at $10 \%$ level.

Table 4. Household per capita Productive and Fixed Assets with and without House

\begin{tabular}{|l|c|c|c|c|c|}
\hline \multirow{4}{*}{ Impact indicators } & \multirow{3}{*}{$\begin{array}{c}\text { Matching } \\
\text { methods }\end{array}$} & \multirow{2}{*}{ Clients } & \multirow{2}{*}{ Non-clients } & & \\
\cline { 4 - 6 } & & & & ATT & t-ratio \\
\hline \multirow{4}{*}{ Household per capita fixed assets(with house) } & Atts & 264 & 108 & 529.9 & 1.15 \\
\cline { 2 - 6 } & Attr & 264 & 106 & 5.09 & 0.16 \\
\cline { 2 - 6 } & Attnd & 264 & 103 & 732.4 & $1.84^{*}$ \\
\cline { 2 - 6 } & Attk & 264 & 106 & 341.8 & 0.83 \\
\hline \multirow{3}{*}{$\begin{array}{l}\text { Household per capita fixed assets } \\
\text { (without house) }\end{array}$} & Atts & 264 & 108 & 242.6 & 1.09 \\
\cline { 2 - 6 } & Attr & 264 & 105 & 263.2 & $1.75^{*}$ \\
\cline { 2 - 6 } & Attnd & 264 & 99 & 288.3 & $1.67^{*}$ \\
\cline { 2 - 6 } & Attk & 264 & 105 & 278.7 & 1.27 \\
\cline { 2 - 6 } & Atts & 264 & 106 & 15.1 & $1.79^{*}$ \\
\cline { 2 - 6 } & Attr & 264 & 108 & 76.1 & 0.65 \\
\cline { 2 - 6 } & Attnd & 264 & 98 & 284.2 & $2.05^{* *}$ \\
\cline { 2 - 6 } & Attk & 264 & 107 & 50.1 & 0.45 \\
\hline
\end{tabular}

Notes: $* *=$ significant at $5 \%$ level; $*=$ significant at $10 \%$ level.

Table 5. ATT Estimation Results of household per capita (food, Total expenditures) and Total poverty severity

\begin{tabular}{|c|c|c|c|c|c|}
\hline \multirow[b]{2}{*}{ Impact indicators } & \multirow{2}{*}{$\begin{array}{l}\text { Matching } \\
\text { methods }\end{array}$} & \multirow{2}{*}{$\begin{array}{l}\text { DECSI } \\
\text { Clients }\end{array}$} & \multicolumn{3}{|c|}{ DECSI } \\
\hline & & & $\begin{array}{l}\text { Non- } \\
\text { Clients }\end{array}$ & ATT & t-ratio \\
\hline \multirow{4}{*}{ Household per capita expenditures on food } & Atts & 264 & 106 & -545.7 & $-2.10 * *$ \\
\hline & Attr & 264 & 108 & -272.9 & -1.58 \\
\hline & Attnd & 264 & 105 & -161.6 & -0.55 \\
\hline & Attk & 264 & 103 & -233.6 & 0.82 \\
\hline \multirow{4}{*}{$\begin{array}{l}\text { Household per capita expenditures on food and non- } \\
\text { food items }\end{array}$} & Atts & 264 & 107 & -644.8 & $-2.3 * *$ \\
\hline & Attr & 264 & 105 & -320.3 & -1.56 \\
\hline & Attnd & 264 & 103 & -204.4 & -0.57 \\
\hline & Attk & 264 & 108 & -296.6 & -1.21 \\
\hline \multirow{4}{*}{ Household square poverty gap ratio (poverty severity) } & Atts & 264 & 105 & 0.001 & $2.1^{* *}$ \\
\hline & Attr & 264 & 108 & 0.0015 & 1.42 \\
\hline & Attnd & 264 & 104 & 0.0012 & 0.536 \\
\hline & Attk & 264 & 108 & 0.0007 & 1.027 \\
\hline
\end{tabular}

Notes: $* *=$ significant at $5 \%$ level; and $*=$ significant at $10 \%$ level. 
Table 6. Results of the Treatment Effect model for Household Food and Monthly Total

(First stage or Heckman's Sample Selection Model)

\begin{tabular}{|c|c|c|c|c|}
\hline Participation in microfinance & Coefficients & $\mathrm{Z}$ & Coefficients & $\mathrm{Z}$ \\
\hline Household head age & .072 & $1.94 *$ & .072 & $1.91^{*}$ \\
\hline Household head age squared & -.00071 & $-2.1^{*}$ & -.00071 & $-2.02 * *$ \\
\hline Household family size & .178 & $3.7^{* *}$ & .178 & $3.45 * * *$ \\
\hline Per capita land & .539 & $2.82 * *$ & .539 & $1.74 *$ \\
\hline Log of per capita land & -.492 & $-2.07 * *$ & -.491 & -1.62 \\
\hline Rubafeleg & .789 & $2.38 * *$ & .789 & $2.2 * *$ \\
\hline Arato & .969 & $5.74 * * *$ & .977 & $3.28 * * *$ \\
\hline Tsenkanet & .655 & $2.80^{* *}$ & .646 & $2.32 * *$ \\
\hline Constant & -3.36 & $-2.25^{* *}$ & -3.36 & $-2.18^{* *}$ \\
\hline Number of obs $=361$ & \multicolumn{4}{|c|}{ Wald chi2 $(14)=70.58 * * *$} \\
\hline Log likelihood $=-175.67388$ & \multicolumn{4}{|c|}{ Prob $>$ chi $2=0.0000$} \\
\hline
\end{tabular}

Notes: $* * *=$ significant at the $1 \%$ level; $* *=$ significant at the $5 \%$ level; and $*=$ significant at the $10 \%$ level.

Table 7. Treatment effects model: two-step estimates (outcome equation)

\begin{tabular}{|c|c|c|c|c|}
\hline Household total and food monthly expenditures & Coefficients & Z & Coefficients & $\mathrm{Z}$ \\
\hline Household head age & 40.62 & $1.65^{*}$ & 12.01 & 0.21 \\
\hline Household workforce ratio & 1927.5 & $3.1 * * *$ & 1540.2 & $3.4 * * *$ \\
\hline Household member with some primary & -559.6 & $-1.7^{*}$ & -348.1 & -1.29 \\
\hline Per capita land & -264.5 & $-1.90^{*}$ & 249.5 & $1.67^{*}$ \\
\hline Other sources of borrowing & -513.9 & $-2.9 * *$ & -420.9 & $-2.2 * *$ \\
\hline Rubafeleg & -197.4 & $-1.76^{*}$ & -1740.8 & -1.44 \\
\hline Participation in micro finance & -1813.4 & -1.09 & -1627.7 & -1.2 \\
\hline Mills ratio & 920.9 & 0.99 & 841.7 & 1.06 \\
\hline \multicolumn{5}{|l|}{ Number of obs $=361$} \\
\hline Wald chi2 $(25)=326.2 * * *$ & \multicolumn{4}{|c|}{ Prob $>$ chi $2=0.0000$} \\
\hline
\end{tabular}

Notes: $* * *=$ significant at the $1 \%$ level; $* *=$ significant at the $5 \%$ level; and $*=$ significant at the $10 \%$ level. 